\title{
Nomadism and Ethics in/as Improvised Movement Practices
}

\section{Vida L. Midgelow (Middlesex University, UK)}

While many dance improvisation practices focus upon qualities of presence and the importance of being "in the moment," a review of these same practices reveals a lexicon that is full of terms suggestive of territories, journeys, flows, connectivities, metamorphosis and transformations. I might point for instance to dancer Eva Karczag who comments that, by being "available to constant flow and change, I can balance at the edge of the unknown and experience fearlessness" (Tufnell and Crickmay 48), or to Miranda Tufnell who asks that dancers "journey without a map" (Tufnell and Crickmay 111), or to the Contact Improvisation ${ }^{1}$ practice of Nancy Stark Smith. She describes contact improvisation jams as "an opportunity to speak this 'common language' across regional borders [...] to play through familiar or new territory" (Koteen and Stark Smith 10).

The language used by these dancers is suggestive of temporal, physical, and geographical terrains. These terrains, and the dances that generate them, embody underlying nomadic concepts. Further, reaching beyond the concerns of performance disciplines and their inherent emphasis upon the kinesthetic and compositional in aesthetic terms, the practices considered here also entail interactions that foreground ethical dimensions. Evoking particularized connectivities between people and spaces, the improvisations discussed in this essay promote non-violent, non-violating, structures. These structures, I will suggest, give substance to a nomadic ethics.

Drawing on my own experiences of dancing and teaching, alongside observing, talking to, and dancing with artists such as Eva Karczag, Miranda Tufnell, Nancy Stark Smith, William Forsythe, and Kirstie Simson, ${ }^{2}$ I seek through this article to reveal these inherent nomadisms and consider their implications for ways of being and knowing. These dancers, all currently teaching and performing in Europe and the U.S., focus upon improvisation as a performance and/or experiential form in which ideas, physicalities, interactions, and compositional forms can be explored. Significantly, the practices these artists have developed arose within what might best be called postmodern experimental dance, as part of (or directly influenced by) the challenges made in the 1960/70s to the very nature of dance by Judson Church Dance Theatre and Grand Union in the U.S. (Banes 1987 and 1993). The practices of these groups and the artists/practices, such as Contact Improvisation, that came out of them positioned improvisation in performance as a way of breaking free from the perceived strictures on and of the body in modern dance forms. Significantly, the assertion of improvisatory practices in the late 1960/70s coincided with the growth of the women's movement. This, and the broader social conditions of the period, encouraged the conception of individual liberty and equality that forms such as Contact Improvisation embodied (Novack 1990). Improvisation was seen as part of this mobilisation for change and was perceived as a method of working that destabilised hierarchical relationships and empowered the performer. Whilst through the eighties and nineties a rather more critical, perhaps cynical, view of these idealistic visions was evident (Banes 2003), improvisation is still a practice in which the refiguring of movement and established norms is valued. Indeed, in an increasingly commodity-obsessed global culture, driven by the requirements of the economy, production, and efficiency, the art of improvisation maintains its status as an alternative mode of performance-one that potentially realigns and reconnects subjectivities. ${ }^{3}$

Nomadic themselves, the lives of the dancers referred to in this article take them across the globe. Similarly, my meetings with each artist reflect a nomadic existence. I met Eva Karczag first in New York, then in London, then at her "home" in the Netherlands. Yet while she has lived in the Netherlands for many years, her parents are from Hungary and her dancing career was developed in the UK, Australia, and the U.S. Karczag describes the effect of these transitions thus:

My teaching methodology reflects my history. From my parents' decision to leave Hungary during the 1956 revolution, where I learnt that one can step into the unknown, through my first love of ballet, which proved not to hold the key to my dancing after all, to my discovery of, and involvement in, somatic-based approaches within dance training, whether it's my rejections, or my embracing of techniques and ideas, all that I have experienced lies embedded in what and 
how I teach. Living and working in different countries and cultures, I also know that inspiration and creativity are fostered through a cross-fertilization of ideas and practices. (Karczag par. 1)

Karczag's travels incorporate migratory and nomadic ${ }^{4}$ boundary crossings, contributing to a rich philosophy and embodied practice based on a wealth of experience. Such boundary crossings are significant features of human existence and contemporary life. Improvisation artists, like many others, carry such global exchange as part of their genealogy in their personal histories and habitations. For many improvisers nomadism is a professional and economic necessity, for they travel the world to perform and teach their work. ${ }^{5}$ Reflecting the effect of this nomadic travelling on her teaching, Nancy Stark Smith writes: "Often over the years I've felt I was 'home' when I was in the same room as my dancing pals, my next of skin-more so than when I was in my own apartment. That sense of homecoming seems to have less to do with geography than with people" (Koteen and Stark Smith 42).

Here the material and corporeal realities of journeying through geographical and bodily territories are placed within a philosophical frame. Drawing on the writings of feminist philosopher Rosi Braidotti, I consider the nature of improvisation in/as nomadism. In Braidotti's writings nomadism, while evolving from the experience of nomadic lives, is not understood literally. Rather, Braidotti notes,

the nomadism in question here refers to the kind of critical consciousness that resists settling into socially coded modes of thought and behavior. Not all nomads are world travelers; some of the greatest trips can take place without physically moving from one's habitat. It is the subversion of set conventions that defines the nomadic state, not the literal act of traveling. (Braidotti 5)

Braidotti developed her concept of the nomad as a feminist figuration of subjectivity through numerous essays and a series of four monographs: Patterns of Dissonance (1991), Nomadic Subjects (1994), Metaphorphoses (2002), and Transpositions (2006). For Braidotti the nomad's identity and stability does not depend on the places she passes through, but on the symbolic home she carries along on the journey. Thus, the nomad is "the kind of subject who has relinquished all idea, desire, or nostalgia for fixity [...] This figuration," she continues, "expresses the desire for an identity made of transitions, and coordinated changes" (Braidotti 22).

Like nomads, improvisers are comfortable with transitions and change; they do not cling to illusions of permanence and stability in their dance. Instead they enact a kind of embodiment that celebrates processes and emphasizes emergence and becoming. These nomadisms, I suggest, reflect particularized ways of knowing and being in dance and in the world. Through these particularized ways of knowing and being there is the potential to refigure subjectivities and promote a connectedness to the changing body and to the bodies of others. This fundamental connectedness to and of the body is important. It is from this somatic ${ }^{6}$ basis that it becomes possible to articulate a particularly nuanced nomadism that, via an emphasis on an embodied thinking-in-doing, improvisers create empathies and journeys through and of the body each time they perform. I argue, therefore, that improvisation enables our understanding of knowledge and subjectivity to be unfixed and deterritorialized, whilst being grounded and located in the materiality of the body and the places in which we dance. Further, I argue that somatically-based improvisation offers ways of being at home without being held by or singularly located in a place, an identity, a memory. I consider these ideas in terms of a particular awareness of and toward the body and through a consideration of improvisatory interactions with others.

\section{Nomadic Thought and the Corporeal Experience of Being in the World}

Braidotti's purpose in developing the figuration of the nomad is to undo the hegemonic construct of the fixed and bounded transcendent subject of modernity. She seeks to replace this with a transversal subject that engages in a re-definition of politics beyond what she considers the traps of territory and identity. Her work establishes a dialogue with other philosophically inclined poststructuralist writers utilizing what she calls the "materialism of the flesh" school of thought (Metamorphoses 5). She draws particular attention to the work of Gilles Deleuze, Donna Haraway, and Luce Irigaray, for these writers 
express related interests in the articulation of the non-unitary subject. As a figuration of non-unitary subjectivity the nomad is the embodiment of lived experience that is fluid, situated, and relational.

The embodied subject in nomadism is understood as a point of overlap between the physical, the symbolic, and the sociological. Thereby, for Braidotti, the body refers to the "human capacity to be both grounded and to flow and thus to transcend the very variables-class, race, sex, gender, age, disability-which structure us." Her notion of the body thereby "rests on a post-identitarian view of what constitutes a subject" (Braidotti in Dolphinjn and van der Tuin 33). This post-identitarian subjectivity does not however refer to an absent "no-body," for while putting forward a philosophical discourse grounded in poststructuralist thought, the feminist and ethical thrust of the nomad is clearly political in nature. The transversal subject she proposes engages in a creative redefinition of politics from below, offering a means for rethinking our own embodied positions and our relationships to one another, and to the environment, in always provisionally located ways.

Such thinking resonates with the types of improvisational practices that I am engaged with. By tracing the interconnection between a nomadic figuration and improvisation, it becomes clear that nomadism is a useful a way of illuminating a configuration of the dancer's body and improvisation as non-unitary and fluid. Further, in a reciprocal fashion, improvisation is an effective way of extending the discourses of nomadism. In tracing these interconnections I ask: What is revealed about improvisation when it considered as nomadism? And, how can the practice of improvisation inform philosophical discourses to develop an expanded politics of subjectivity and knowledge?

Such debates, while grounded in artistic practices, reach beyond dance to discourses in which human agency-our ability to adapt, communicate and respond to our environment-become the concern. As music and literary scholar Daniel Fischlin writes,

If improvisation is a key way in which humans collectively adapt, communicate, and respond (both consonantly and dissonantly) with their environment; if it is a ubiquitous trans-cultural practice that points to an underlying quality of what it means to be human; if improvised discourses articulate ideas only to be found therein, testing the limits of our capacity to think new thoughts, to see beyond the constraints of current notions of freedom of expression; then there is a profound relationship to be recognized between improvised musical discourses and other more expansive discourses in which other forms of human agency are at stake.

(Fischlin 4)

Now, there are a lot of "ifs" here, but by using the parable of the gypsy who surmounts the impossible difficulty to become a great jazz musician, Fischlin usefully articulates the ways in which improvisation, as both a life and performance practice, has wider potential in/as discourse and in the world. The story he draws upon is entitled "Resurrection of Django," by the Uruguayan writer Eduardo Galeano. Fischlin suggests that this tale points towards what he calls the unnamable or unspeakable component of improvisation and the "secret pact" grounded in transaction (here expressed as between player and instrument that are inseparable), giving rise to unpredictable directions (2). Using this example and others, Fischlin suggests that "improvisatory agency has an especially pressing, unexamined, and under-explored reality that demands our attention" (3).

In the context of dance, this demand for our attention can be understood both in terms of the significance to the individual, through the deep experience of the body that improvisation can evoke, and through the importance of the intersubjective interactions that are the basis of group improvisations. Significant social ethics, grounded in the somatic, are formed within the shared "secret pact" that often, as discussed by Fischlin, remain unnamed and unpredictable in dance practice.

In Fischlin as well as in Braidotti, socio-political and philosophical concerns are crucially grounded and made "real" through narrative forms and references to lived experience. Indeed Braidotti's work develops at the intersection of feminist discourse, poststructuralism and, in phenomenological terms, the lived experience of being in the world. In a related mode I weave together movement descriptions and personal narratives, locating ideas in the particular and the lived. This offers a way through which the 
experience of practice and theories can become purposefully and meaningfully interconnected. This approach relates to the self-reflexive methodologies promoted by (auto)ethnography and is phenomenological in nature. While the use of such first-person narratives have often been overlooked in academic writing (Midgelow 2011), and risk being perceived as self-indulgent—narcissistic even—I seek to locate the importance of experience within thinking (and writing). As I have argued in previous writing, in doing so I am "Valuing our connectedness to skin, to bodies-it is from here, our first-person experience in and of the world, that we start to making meanings, to make sense" (Bacon and Midgelow 5). Purposefully operating as a means to address the "secret pact," this approach is a way to name the unnamed, while also reflecting the nomadic desire to seek and activate different, alternative, ways of being and knowing in the world-and these are important political acts.

\section{The (Changing) Body as “Home”}

Summer 2011.

My plane journey from Birmingham, UK to Newark, USA was uneventful, although I get off the plane with a bloated stomach and swollen feet (uncomfortable and typical following long haul flights). I arrive in New York City at St. Marks Church. This church cum dance space resonates with complex histories through time and with my previous visits to see performances, attend workshops and meetings.

I am here to attend a workshop with Eva Karczag. It is summer. It is hot. The double doors at the front of the church are open and the bustle of the city goes on around us, as lorries and people pass by and the sounds of horns, shouting, and the click of heels echo around us.

I find myself immersed in images of the body, skeletal forms experienced and extended through improvisation. Photographic images of the rib cage (Eva calls it a rib basket), are passed around the group. The images show the shape of the ribs, curving and connecting, from a range of angles revealing the three-dimensionality of the space they form in our bodies.

Guided by Eva's calm tones I am dancing without knowing where I am going. An interior image sensation of the rib basket moves me, as I move with it. The sensations are complex and multifaceted. This is a place of knowing that is fully embodied, a place of knowing that is aware of how much it does not know, leading me to an elsewhere. (Author's reflections, August 2011)

This embodied experience, taking place within the highly nomadic city that is New York, proffers an interesting insight into the possibility of the nomad who carries her home with her. So what is "home" to the improvising nomad? What is it that is returned to while crossing seas and passing through borders? Home for the dancing nomad is that which they carry with/are them. The flesh, bones, and memories of the body as formed with/in shifting geographies and histories are home and this home is returned to again and again. Yet, although we carry this home with us, it is not static; it is ever-changing in and through time. Our cells die and are replaced; our muscles work, rest, ache; we survive traumas and we age. In every revisiting, every new experience, different layers and connections are formed in the bodymind, fashioning a subtly ever-changing body as home.

Karczag's work is based in Alexander Technique ${ }^{7}$ and uses touch and visual images of internal spaces to enable shifts in the perception of the body as home. In the workshop described above she was working from representations in photographs to a repositioning of these as imagined locations in the (my) body, and from here to a material embodied encounter as physical and emotional sensation. It is in these shifts of encounter and the sensate that the possibilities of the dancing body as a reimagined, reexperienced "home" are strong, pulling me deeply into their fold, such that while many others dance around me I am engulfed within the embodied experience of moving.

Thus somatically-based improvisation pulls attention to the changing body as home, through repeated revisiting and a heightened attention to ever-shifting details. When dancing with an internal image, described in the workshop notes above, there is space that is both intensely aware of the familiar (a range and scope of movement this comfortable and a body that one knows well), and simultaneously responsive to the pleasure of experiencing the body differently and perceiving it anew each time. 
The notion of a home that is changing, a body in flux, echoes Braidotti's positioning of the nomad as radically anti-essentialist and in a constant state of "in-process," which Braidotti refers to as "as-if." The practice of "as-if," for Braidotti, is a "technique of strategic re-location in order to rescue what we need of the past in order to trace paths of transformation of our lives here and now" (Nomadic Subjects 6). In this way, nomadism forces subjective specificity according to lived, complex experience and orientation, within multiple discourses and physical positions. Indeed, working with/as the "changing body as home," the improviser constantly practices the state of "as if." This state can be considered an effective means through which to mobilize the nomad who, Braidotti argues, recognizes the specifically located nature of bodies (who are more than the sum of their organs), and the importance of embodiment that is an integral part of ourselves and our lived experience, which forces specificity, multiplicity, and complexity without endless slippage and relativism.

\section{Improvisatory Becomings and Polyglotism}

The body, and our embodied and material experience of being in the world is, in a nomadic figuration, non-linear and non-unitary. This is akin, Braidotti notes, to Haraway's configuration of the cyborg ("Posthuman" 8). Capable of multiple (but not endless) variations, Braidotti writes that

a radically immanent intensive body is an assemblage of forces, or flows, intensities and passions that solidify in space, and consolidate in time, within the singular configuration commonly known as an "individual" self. This intensive and dynamic entity does not coincide with the enumeration of inner rationalist laws, nor is it merely the unfolding of genetic data and information. It is rather a portion of forces that is stable enough to sustain and to undergo constant, though, non-destructive, fluxes of transformation. ("Posthuman" 7)

Nomadism and the body are cartographically represented in Braidotti's work as in-between and interconnected. This interconnected view enables the rethinking of power processes and representations such that the "nomadic subject is flows of transformation without ultimate destination. It is a form of intransitive becoming: it is multiple, relational, dynamic." Braidotti argues, "You can never be a nomad, you can only go on trying to become nomadic" (italics in original, Metamorphoses 86).

Tracing the intersections between Deleuzian "becomings" and becoming nomad, she pursues the line of becoming-insect/woman/imperceptible to describe a becoming in which unlikely encounters and unexpected sources of interaction of experience and of knowledge occur. Her vision of flow and encounter, interior and exterior are related to the Deleuzian "Becoming-animal," and her "becomings" are marked by processes of "empathic proximity and intensive interconnectedness" (Metamorphoses 8). It is such paths that are embodied in the improvisations described below.

July $15^{\text {th }}, 2011:$

I am dancing in the MY11 studio on a Friday afternoon and I am becoming Other. I have set myself improvisation tasks that seek to evoke contrasting physical states...

Becoming 'insect' ...

Becoming 'reptile' ...

Becoming 'bird' ...

My instructions to self are to work with the image of these creatures as an internal stimulus and to work to embody them. And to, build upon the sensations these images evoke in the body-the tendencies, tensions, twitches, twists, and turns-such that a response to and dwelling in, becoming 'animal,' becoming 'other' occurs.

The task here is to use the images of 'becoming animal' not to provide form, but to provide sensation/inspiration.

July $23^{\text {rd }}, 2011$ :

Developing the 'becoming insect' improvisation (below) I focus in upon the sensations on/of the skin.

Imagine ants crawl across your hand, arm, shoulder ... 
They move across your cheek, back ... Imagine a swarm covers your body ...

Let the sensations evoked give rise to movement ... note the changing texture of the skin, pay attention to the detail to the smallest (re)action.

I feel skin on my hand beginning to flicker, moving into my fingers. I isolate fragments of the body as they shiver, flicker, and twitch. My skin is no-longer my own. Entering deeper into the body, my spine bristles-I want to shout, to scream-as the internalized movement shudders on.

July $25^{\text {th }}, 2011$ :

In a virtual exchange with Professor Frank Chamberlain via Vimeo, he too becomes insect. Following my task above, he dances-filming his dance simply through a webcam.

Chamberlain writes: I watched, then I read and I watched again. I noticed that as I watched I felt distanced, that I was receiving only through my eyes ... I wanted to feel it on my skin. I watched again, this time allowing my body to respond simultaneously to movement and text, feeling sensations on my skin.

Next I turned on the camera, stood up and moved whilst playing the video. After a few moments I left your video and focused on my own movement in response to the text.

Afterwards, without explanation (and without any request for feedback), I played both videos for Julian [young son]-he saw spiders and butterflies in both pieces and also caterpillars in mine.

(Adapted from author's blog entry at http://danceimprovisationpractice.blogspot.com, July $15^{\text {th }}-25^{\text {th }}$, 2011)

In "becoming-insect" this improvisation avoids any mimetic approach, which would render the movement experience flat and banal. Rather, through this improvisation, there is an embodied figuration of alterity-experienced as a hybrid form that is unfixed by prior forms and bodies-and the potentiality of metamorphosis.

Braidotti, exploring becoming-insect as a particular figuration, suggests that the insect is "a border-line figure, capable of bearing different meanings and associations" (Metamorphoses 150). For her the insect body is related to the potential challenge offered by the monstrous other and the alien, for images of insect express deeply rooted anxieties about cultural and biological mutations. Here the potential of the insect is found by drawing on the sensation and image of insect-ness. The movement improvisation, by transforming the body, attains a level of bodily intensity that is transgressive, shifting awareness to that which is beyond the everyday and open to difference.

Indeed, being open to transformation and difference is a key feature of the improvisatory movement practices considered here. Affecting such transformations in practice often entails a reconsideration of known movement practices and the establishment of circumstances that trigger other, more diverse, movement patterns to come to the fore. This commitment to finding alternative ways of moving requires a deep understanding of established norms and a high level of self-consciousness, such that the dancer can resist or resituate codified languages and established ways of dancing. Thereby improvisers have established complex frameworks to produce hybrid, deterritorialized ways of being and moving.

For example, taking a very different approach to my becoming-insect improvisation above, we can see in William Forsythe's work sets of complex systems that enable the body to be upturned and redirected. His improvisatory system, described in Improvisation Technologies: A Tool for the Analytical Dance Eye, articulates movement activities that substantively reorient the internal geometries of the body and the body in space. Establishing tasks with specific foci he draws the improviser's attention, for example, to the way in which positive and negative spaces are formed in and around the body, the way interconnecting "lines" cross the body and how space might be formed and rotated through different planes. These activities challenge the dancer's habitual patterns and perceptions, bringing about newly configured relationships to the body and to space-effectively transforming established patterns and hierarchies. 
Dec. 2010:

In my class today with third year students we have been working through the task "Writing-U-ing and Oing transformative operations." This task, from Forsythe's Improvisation Technologies, requires the students to imagine tracing curving lines extending out of their joints and limbs. Refocusing their attentions to imagine points of the body moving around different points of axes they are writing their bodies anew.

A knee rotates inward as the hips swing back, a foot twists and the shoulder arches out through a long curve. Their bodyminds work hard to hold onto the multiplicities of information, and to attain the complex multi-directionalities. Familiar patterns are deconstructed and their ingrained movement languages are shifted, and other potentialities come into being. (Author's Reflections, Dec. 2010)

Setting up such circumstances in which movement can emerge from within the moment, refiguring both codified and personal practices allows polyvocal performance and practices to arise. For observing Forsythe's dancers, it is clear that whilst trained within codified forms (most visibly ballet) they are not fixed by established techniques. Rather Forsythe enables familiar materials to be refigured in new contexts, deliberately mistranslated into different planes and formed through shifting trajectories. As Forsythe, speaking of Finnegans Wake, remarks,

For me it's a paradigmatic work: you can't translate it because it is already in many languages, and their coexistence is the whole point-I really admire this sense of the world within language, language as a connection machine, bringing apparently different, hermetic ideas together and exploding them into each other. This dissolution of borders between languages is like the dissolution between styles of dance: what's the difference between ballet and hip-hop? Ballet and tap? Ballet and non-ballet? There is no border, because it is the body. (Sulcas 46)

In Braidotti's terms, Forsythe as improviser is a polyglot. Able to speak in many languages and different registers, resisting the controlling codes of any single mode. In her book Nomadic Subjects, she describes the nomadism of the linguistic polygot: "The polyglot is a specialist of the treacherous nature of language, of any language" (Nomadic Subjects 8). Referring to Lacan and Kristeva, she observes that no language is really a mother tongue. Rather, languages "carry the name of the father" (11). Informed by feminism, it is useful to think of languages as vehicles of patriarchy, and to remember that subjects are independent-to a certain extent-of official languages. It is the ability to pass between languages and methods of communication that deterritorializes a subject for the polyglot "has no vernacular, but many lines of transit" (13).

The improviser as a deterritorialized subject challenges hierarchical practices and knowings. She refuses to operate with any singular movement practice (or at least not being held by the codes of a predetermined form) and, perhaps most importantly, she refutes that any particular way of moving the body has more value than any another. The shuffle is as valid as the hop and stillness as important as action, as the improviser slips between languages that form difficult-to-translate combinations and notyet-known possibilities.

Actualizing dancing as otherness, and the alterity of the not-I within the "I," as well as with the Other that is within me, the improviser as polyglot enables home be formed not in the nostalgia of the known-but in a figuration that is complex and that encompasses changing, shifting landscapes of the unknown.

\section{Intersubjectivities and Nomadic Ethics}

Here I shift the emphasis from the potentialities of the solo improviser as nomad to that which emerges through group interactions with others; the exchange between two or more dancers in non-discursive dialogues. In these danced exchanges between people, movements, images, patterns, and structures arise that are located in "in-between"-belonging to both no one and everyone. This exchange is founded upon intersubjective interactions that are kinesthetic, intercorporeal, imaginary, and playful. 
Summer 2010:

Light pours into the dance studio at Roehampton University. I spent this afternoon watching a group of dancers work with Kirstie [Simson], watching the figures dance together, watching them watch each other. These interactive gazes, mine included, are as often-possibly more often-felt and sensed (haptic?) gazes, rather than visual ones ... I note an openness to the room and pay attention to this as I might if dancing - allowing rather than doing, being rather than acting. I remind myself of these well trodden but, in this moment, significant phrases-mantras for ways of being. These ideas resonate in my body, enabling a state of awareness (attentiveness) to come into play.

\section{A shift-}

The dancers in the group begin to open their attentions-the shift from inner to outer is palpable (and some are more ready than others). An improvisation as a continuation of warming up. Kirstie suggests that the group dance together in order to start to get to know one another ...

Like satellites-shifting in and out of connections.

Relationships_-searching for intimacies, following impulses, imitations, and echoes.

Movement-functional, everyday, extended, individuals embodied 'styles' and qualities.

Creating Movement/Sound Worlds

Among an experienced group of improvisers, ways of interacting quickly arise-levels of acceptance are high. The first moment of laughter and vocal exchange whilst dancing gives rise to a moment of uncertainty that quickly passes.

(Adapted from author's blog entry at http://june2010.posterous.com)

These exchanges between dancers might usefully be considered in ethical terms. In Transpositions, Braidotti suggests that nomadic ethics are not just bound within justice, human rights, and the law, but are also embedded in concerns with social agency and the management of power relations. Simson's improvisational practice offers a heightened sense of the importance of agency within the framework of what constitutes a social practice. The improvisation established by Simson is unrestricted by any preset or pre-agreed structure or score. Entering the dancing space (a studio with no particular orientation), the dancers respond tacitly to impulses emerging in their bodies or from the environment-a sound, a colour, a physical sensation, an atmosphere. The improvisers maintain a high degree of awareness of each other in the space and form relationships that echo, contrast, harmonize and/or redirect the movement ideas, images, and energy present. They use touch and come into full contact with each other, taking and giving weight, using both extended pedestrian vocabularies and conventions drawn from Contact Improvisation. Dancing with a particular sensibility towards others, the interactions and modes of touch that pass between the group are largely unspoken, operating like a secret pact (to recall Fischlin). This secret pact is understood both through a shared (but generally unspoken) knowledge of Contact Improvisation, but also one that develops through the duration of the improvisation itself. Through the dancers' close attention to each other and the taking of time to "know" each other's potentialities in performance, implicit "rules" and "games" are developed. In this process there is an emphasis upon equality in exchange and an unspoken acknowledgement of difference. It is this insistence on the potential for individuation and singularities that allows an ethical environment in which exchange, rather than the power of pre-knowledge, is to the fore.

Taking time and being sensitive to individual potentialities leads to an implicit ethics being present in the relations between dancers. In this way Simson's improvisation (akin to many others informed by Contact Improvisation and martial arts) problematises knowledge as an absolute and offers an ethical environment in which relational practices give rise to knowings as shared between dancers which belong to no one and everyone. This illuminates the way in which ethical relations emerge between subjects when one recognizes that self and other are incommensurable. Thus, in improvisation the ethics of the encounter is found in the capacity of the dancers to be open to the other, whilst engaging in processes of transformation - not to become other, but to pay attention to that which is formed in the space in-between.

It is fair to say that this encounter does not always run smoothly-the capacity to hold and be attentive to such non-violent, non-violating, and shared territories is hard to do; however, dancers like Simson train themselves towards a heightened sensitivity that supports these processes. In doing so, dancers 
may find in improvisation a radical refiguration of intersubjective exchange in which a nomadic ethics is lived within the form itself. Thus, what comes forward is an approach to the Other, in which the Other is not consumed, but rather is part of a shared practice in which risk and ambiguity are possible, in which the dancers implicitly acknowledge the need to be vulnerable to the process, open to the consequences and to the effect of each other's responses to the Other and one another.

Based on an ethics of relational practice, the iterations between improvisers could be considered a "civic engagement" in which responsiveness and responsibilities are shared, complex, and diffuse as the dancers implicitly embody a form of active citizenship. Forming nomadic assemblages, improvisers transform passive modes of being into active relations, giving rise to shared futures for, as Braidotti writes, "To desire a vibrant, affirmative and empowering present is to live in intensity and thus to unfold possible futures" (Transpositions 154).

Such futures, I suggest, are embodied and expanded by the Global Underscore, an improvisatory practice by Nancy Stark Smith. The Underscore is described by Stark Smith as "a framework that guides dancers through a series of 'changing states,' from solo deepening/releasing and sensitizing to gravity and support; through group circulation and interaction, Contact Improvisation engagements, opening out to full group improvisation with compositional awareness, and back to rest and reflection" (Koteen and Stark Smith 90-98). The score, developed as a graphic since the early 1990s, provides a structure for practicing Contact Improvisation. As a framework it holds within it the establishment of important "ways of being" that underpin Contact work, and also indicators of the range of types of interaction that might evolve within an improvisatory session. For example, starting with tasks that draw the participant/performers into the space, by "Arriving Energetically" and "Arriving Physically," the score develops to explore extended movement into the spatial environment, evolving from the "Skinesphere" to the "Kinesphere" and then, through incremental steps, introduces "Overlapping Kinespheres" and the full use of touch via "Engagement." In latter stages the dancers might find or develop for instance "confluence," "divergence," "collision," or "tangents."

This form shares many features with Simson's practice, but when developed as a global practice it evokes a connectivity that extends beyond the interpersonal to interactions that have the potential of the biopolitical. Conceived by French dancer Claire Filmon, the Global Underscore is an annual event that takes place on the June solstice, during which dancers at many sites around the world practice the Underscore simultaneously. These simultaneous dances may be connected via technology (live streaming as in the example below), but more importantly are embedded with a sense of connectedness that comes with the knowledge of it as a shared global practice that spans countries, land masses, groups, and individuals.

July 2012 (Somatics and Technology Conference, Chichester, UK):

Marlon [Barrios Solano] is live streaming the "Underscore" performance being undertaken in different locations in the world. ${ }^{8}$ He moves through the studio filming the dance here in this space whilst, projected on the studio wall, dancers from studios across the world are preparing to dance the Underscore.

The dancers start to disperse and enter the first movement stage of the underscore: "Perambulation."

Bells lightly tingle in the space and bamboo touches bamboo. Feet fall-passing through space, stepping on foot in front of the other, the dancers walk and run. Noting other people-sharing the space and arriving.

The room stills as the group begins the "Small Dance" and the dancers draw in their focus to note the detail dance inside their bodies. All standing and facing in the prearranged direction, the video projects back to each dancer her own dance, and that of others, in a live feedback loop and they watch themselves entering this dance. The movements continue and are made possible in/by stillness. Connecting across the world in their imaginations and via the screen image, the dancers perform the "Small Dance" at the same time. 
Entering the next phase of the underscore, "Skinesphere," dancers roll on the floor-easing into different surfaces of the body ... the mass of the body held in skin contacts the floor. Travelling through the underscore simultaneously with the dancers on screen, the moving develops energetically. Pairing, they take flight and turn. Seesawing through and around ... their dancing comes together and round about. Maintaining physical contact in a delightful flow ... legs splitting, spiraling as the lift rotates ...

I feel a desire to shift in space to reorient my body to theirs ... to join the connections between dancers, here and across the world. (Author's Reflections, July 2012)

Here, in a micro-politics, a way of being with others is played out. Resisting the commodification of mass culture, this shared practice evokes the responsibility of all of us to resist our position as subjects of control and to resist differently. Enlivening in-between spaces the Global Underscore, and in related ways the other forms of non-discursive improvisation practices considered here, make plausible the idea of a radical ethics of civic engagement as improvisation.

\section{Conclusion: Political Action and Different Ways of Knowing}

The nomadism of the improviser enhances skills and knowledge of various kinds. Of vital importance among these are the ethical responsibilities to a changing and ever-evolving dynamics of the body and of other dancers. Through processes of curiosity and questioning, improvisers evoke a physical and intellectual becomings-toward-the-world. Their nomadic becomings challenge the subjectification processes that precondition hierarchies of "home" and "knowledge."

In a state of constant transition, the improviser never arrives; her dance is never complete. Yet whilst improvisation presents opportunities for things unplanned to emerge in the moment, this does not mean, as Braidotti so clearly articulates, that nomadism is a form of limitlessness. On the contrary, the openness through which nomadic becomings are continuously re-configured, which whilst complex to grasp, is an ethical relation and part of a sustained engagement.

Therefore the figurations of improviser-as-nomad does not imply an erasure of memory or un-locatable experience but unravels a becoming-responsive that creates positive energies and multi-layered visions of the subject that are dynamic. Accentuating that we live in a world that is always in transition, improvisation becomes a living map towards a nomadic and transformative account of the embodied subject. Thus it is possible to recognize the improvisational nature of the nomad and the nomadic nature of improvisation. The improviser is then the ideal nomadic subject, able to enact with the territory she finds herself in and adapt to complex conditions. I suggest then in tracing the interconnection between the nomadic figuration and improvisations it becomes clear that nomadism is a useful way of illuminating improvisation and, in a reciprocal fashion, improvisation is an effective way of extending the discourses of nomadism. For, I suggest, improvisation is the consummate form of nomadism.

\section{Notes}

${ }^{1}$ Contact improvisation (also known as $\mathrm{Cl}$ or Contact) is a duet form of experimental dance developed initially by Steve Paxton. The form evolves from two moving bodies following points of contact between them in an improvised sharing of weight giving and supporting. (See Novack 1990 for a full description and analysis of $\mathrm{Cl}$.)

${ }^{2}$ Eva Karczag has practiced and taught explorative ways of art making for the past three decades. Her performance work and her teaching are informed by dance improvisation and mindful body practices (including T'ai Chi Ch'uan and Qi Gong), the Alexander Technique (certified teacher), Ideokinesis, and Yoga.

Miranda Tufnell is a dance artist, writer, and teacher in movement and imagination, based in the UK. She is also an Alexander teacher and craniosacral therapist. Her work is concerned with improvisation, embodiment, and our imaginative connection to the world around us. With Chris Crickmay she has co- 
authored two handbooks on sourcing creative work entitled Body Space Image (1990) and A Widening Field (2004).

American dancer Nancy Stark Smith first trained as an athlete and gymnast, leading her to study and perform modern and postmodern dance in the early 1970s, greatly influenced by the dance/theater improvisation group the Grand Union and the Judson Dance Theater breakthroughs of the 1960s in NYC. She has been central to the development of Contact Improvisation, working extensively over the years with Steve Paxton and others.

Raised in New York, William Forsythe danced with the Joffrey Ballet and later the Stuttgart Ballet, where he was appointed Resident Choreographer in 1976. In 1984, he began a 20-year tenure as director of the Ballet Frankfurt, where he created works such as Artifact (1984), Eidos:Telos (1995), Kammer/Kammer (2000), and Decreation (2003). After the closure of the Ballet Frankfurt in 2004, Forsythe established a new, more independent ensemble, The Forsythe Company.

British dancer Kirstie Simson is one of the key exponents of Contact Improvisation. She has been pursuing contact improvisation and the art of improvisation in performance over the course of the last twenty-five years. She works extensively, performing and teaching throughout England, Europe, and the USA.

${ }^{3}$ There has in recent years been an increased interested in the practice, history, culture, and discourse of improvisation by dance scholars, although publications in this area are still limited. Particularly significant texts relating to postmodern dance improvisation include Buckwalter's Composing while Dancing, Cooper-Albright and Gere's Taken by Surprise, Foster's Dances That Describe Themselves, and Goldman's I Want to be Ready.

${ }^{4}$ In working with her figuration of the nomad, Braidotti is careful to distinguish the nomad from the exile or migrant. Given the very real forms of exile and forcible displacement now practiced globally, Braidotti feels that issues of exile are much too serious to be used playfully as a metaphor. She is also wary of the metaphor of "migrant," who goes from one point to another with a clear destination. The migrant is more socially marked than the nomad; the migrant tends to exist within a subculture and does not easily make links with inhabitants of the hegemonic culture in which she arrives.

${ }^{5}$ This gives rise to a myriad of questions about the existence of nomadism within international networks, the reach and status of improvisation and its translation across continents. While not the focus of this article, the effect of the cultural, financial, and geographical conditions in which improvisation takes place are questions that resonate in the background of these artists' lives.

${ }^{6}$ Somatics is a field that employs holistic body-centered approaches to assist people in integrating and transforming self through movement and awareness practices intended to promote psycho-physical wellbeing. A useful history of the development of somatics in dance can be found in Martha Eddy's "Brief History of Somatic Practices and Dance."

${ }^{7}$ Alexander Technique was developed by F.M Alexander and uses "hands on" methods to change (movement) habits in our everyday activities. See http://www.stat.org.uk.

${ }^{8}$ This event was live streamed at http://www.dance-tech.net/.

\section{Works Cited}

Bacon, Jane and Vida Midgelow. "Writing the self, writing the choreographic." Choreographic Practices Vol. 2 (2011): 3-7. Print.

Banes, Sally. "Spontaneous Combustion: Notes on Dance Improvisation from the Sixties to the Nineties." Taken by Surprise: A Dance Improvisation Reader. Ed. Ann Cooper Albright and David Gere. Middletown: Wesleyan University Press, 2003. 77-89. Print.

---. Democracy's Body: Judson Dance Theatre, 1962-1964. Durham: Duke University Press, 1993. Print. 
---. Terpsichore in Sneakers: Post-Modern Dance. Middleton: Wesleyan University Press, 1987. Print.

Braidotti, Rosi. Transpositions: On Nomadic Ethics. Cambridge: Polity Press, 2006. Print.

---. "Posthuman, all too Human: Towards a New Process Ontology." Theory, Culture \& Society 23.7-8 (2006): 197-208. Print.

---. Metamorphoses: Towards a Materialist Theory of Becoming. Cambridge and Malden: Polity Press, 2002. Print.

---. Nomadic Subjects: Embodiment and Sexual Difference in Contemporary Feminist Theory. New York: Columbia University Press, 1994. Print.

Buckwalter, Melinda. Composing while Dancing. Madison: University of Wisconsin Press, 2010. Madison. Print.

Cooper-Albright, Ann and David Gere, eds. Taken by Surprise. Middletown: Wesleyan University Press, 2003. Print.

Dolphinjn, Rick and Iris van der Tuin. "'The notion of the univocity of Being or single matter positions difference as a verb or process of becoming at the heart of the matter': Interview with Rosi Braidotti." Ed. Rick Dolphinjn and Iris van der Tuin. New Materialism: Interviews \& Cartographies. Ann Arbor: Open Humanities Press, 2012. 19-37. Print.

Eddy, Martha. "A Brief History of Somatic Practices and Dance: Historical Development of the Field of Somatic Education and its Relationship to Dance." Journal of Dance and Somatic Practices 1.1 (2009): 5-28. Print.

Fischlin, Daniel. "Improvisation and the Unnameable: On Being Instrumental." Critical Studies in Improvisation / Études critiques en improvisation 5.1 (2009). Web. 5 Jan. 2013.

Forsythe, William. William Forsythe: Improvisation Technologies: A Tool for the Analytical Dance Eye. Germany: Digital Arts Edition, ZKM 2003.

Foster, Susan. Dances that Describe Themselves. Middletown: Wesleyan University Press, 2002. Print.

Goldman, Danielle. I Want to be Ready. Michigan: University of Michigan Press, 2010. Print.

Karczag, Eva. "Creating a body, promoting independent creative thought." CORPUS. 12 May 2010. Web. 05 Jan. 2013.

Koteen, David and Nancy Stark Smith. Caught Falling. Northampton, MA: Contact Editions, 2008.

Midgelow, Vida L. "Sensualities: Experiencing/dancing/writing." New Writing: The International Journal for the Practice and Theory of Creative Writing (2012): 1-15. 9 July 2012. Web. 5 Jan. 2013.

Novack, Cynthia. Sharing the Dance: Contact Improvisation and American Culture. Madison: Wisconsin Press, 1990. Print.

Sulcas, Roslyn. "Both a New World and the Old Made Explicit." William Forsythe: Improvisation Technologies: A Tool for the Analytical Dance Eye. Germany: Digital Arts Edition, ZKM 2003.

Tufnell, Miranda and Chris Crickmay. Body, Space, Image. London: Virago Press, 1990. Print. 